\title{
Development of a New Method of Aggregate Treatment in the Technology of Lightweight Concrete-Wood Concrete
}

\begin{abstract}
S. S. Uderbayev
K. A. Bissenov

Doi:10.5901/mjss.2014.v5n20p2682

Abstract

The article deals with the results of the research and development of a new method of the aggregate preparation in the technology of lightweight concrete-wood concrete. It is developed as a new method for gentrification of organic aggregaterice husk in the electrochemically activated cathode water with addition of a quicklime of $1 \%-1.5 \%$ by weight of water and adjusting the $\mathrm{pH}$ of the liquid medium to 14-16. It is specified that the addition of quicklime in the treatment of the alkaline water and soaking the organic aggregate in it greatly intensifies a strength gain of wood concrete. Technical novelty of the method is confirmed by the RK preliminary patent no. 16644. The results of the conducted experiments led to the enhancement of wood concrete strength made by the proposed method of organic aggregate up to $2.45 \mathrm{MPa}$ in the rice husk, $2.6 \mathrm{MPa}$ in the wood flake, 2.35 MPa at guza units, 2.2 for sliced rice straw, and $2 \mathrm{MPa}$ for broken rice reeds.
\end{abstract}

Keywords: method of treatment, gentrification, rice husk, wood concrete, strength, fly ash cement stone.

\section{Introduction}

It is known that a wood concrete is a variation of a lightweight concrete manufactured from selected cement mixture, organic aggregates, chemical additives, and water. Organic aggregates may be of different origin and different shape of particles (crushed waste of wood species, cane chaff, fire hemp or flax, rice husk and straw, sunflower husk, etc.). The technology of manufacturing products from wood concrete is largely closer to the technology of products from normal concrete. Runout of wood concrete products is well arranged and has spread to Russia, Austria, the Netherlands, the Czech Republic, Poland, Japan, and Canada. In Europe, a wood concrete is known as "Dyurizol" (the Netherlands, Austria, and Switzerland) and "Pilinobeton" (Czech Republic).

Ventures for the production of wood concrete products in the CIS through molding expand both the range of manufactured products and the type of aggregate. Moreover, the use of a particular type of aggregate, whose reserves are less exhausted, is specific for each region.

As is well known, agricultural waste, such as fire flax, kenaf, rice straw, husks, and cotton stalks, can be used in the production of wood concrete in addition to the aggregates of wood waste. The production of wood concrete in Southern Kazakhstan can be based on the use of agricultural waste and industrial waste-the CHP ash.

Annually, in only one Kyzylorda region about 40 thousand tons of rice husk is produced in the processing of paddy rice. Agricultural waste is always renewable, and its use certainly contributes to the conservation of resources and is one of the most topical issues. The density of rice husk is $737 \mathrm{~kg} / \mathrm{m}^{3}$, and a bulk density is in the range of 80 to $150 \mathrm{~kg} / \mathrm{m}^{3}$. Compared with the wood, the content of inorganic matter and protein compounds in the rice husk is higher; at the same time, there are only pentosans of hemicelluloses.

With a view to resource conservation, it is expedient to increase the pace of use of agricultural waste in the production of wood concrete products.

Wood concrete product is a building block of low strength because of the different nature of the aggregate and mineral binder. The use of agricultural and industrial waste for the production of wood concrete not only contributes to the development of the industry of building materials but also addresses the issue of the use of large capacity waste that essentially improves the environmental situation of the region.

Despite the numerous studies in the field of improving the technology of wood concrete, further exploration of the possibility of effective use of industrial and agricultural waste and thereby the improvement of the physical and mechanical properties of the final product are very important.

In particular, the main research directions in the technology of wood concrete are as follows [1-5]:

"development of theoretical foundations of wood concrete with desired properties and lower consumption of cement; 
- improving the physical and mechanical properties of wood concrete, enhancing its strength, biological stability, fire resistance, and durability;

- development of effective ways to treat the organic aggregate; and

- development of proposals to expand the raw material base for the production of wood concrete."

A common method of treating an organic binder is its long soak in water of normal temperature $\left(18-20^{\circ} \mathrm{C}\right)$ that increases the strength of wood concrete by $10 \%-15 \%$ compared with wood concrete of the untreated aggregate. However, the soluble substances are extracted in the soaking process, and the polysaccharides continuing a hamper of cement hardening are left. Treatment with hot water complicates the processing technology, and a long maceration requires more storage space. as follows:

The early studied research work analysis shows that the technological factors for the aggregate gentrification are

1. The physical and chemical processes occurring in wood concrete under its production are influenced by the extractive water-soluble substances that have a significant effect on the hydration and hardening of cement, crystallization and structure formation in the cement stone, formation of structural relations in the contact area of the aggregate and the binder, and ultimately, strength of wood concrete itself.

2. Relatively, the effective soaking is the aggregate soaking in water at water-solid ratio of 1:10 and 1:15. Thus, there is a process of removing or extraction of soluble substances from the body of organic aggregate. Despite this process, the given method does not provide high-gain strength of wood concrete products. Therefore, one of the areas of research will continue to be a development of the most effective ways to neutralize the harmful substances in the organic aggregate and treat it to obtain the desired properties.

\section{Materials and Methods}

Technology features of wood concrete make specific demands on feedstock to produce wood concrete meeting the requirements of GOST 19222-84 [6]. The raw materials used for the experiments were Portland cement, quicklime, fly ash of the Kyzylorda CHP, and an organic plant aggregate-rice husk and chopped stalks of rice straw.

A range of methods of physical and chemical analysis were used under the study.

Water absorption was determined on the dice of $70 \times 70 \times 70 \mathrm{~mm}$ produced by the proposed technology. Water saturation is made within 48 hours under the water level above the top of samples of at least $2 \mathrm{~cm}[6]$.

Water absorption of the sample (\% by weight):

$W=\left(m_{2}-m_{1} / m_{1}\right) 100,(1)$

where $m_{1}$ is the mass of the dry sample $(\mathrm{g})$ and $\mathrm{m}_{2}$ is the mass of the water-saturated sample $(\mathrm{g})$.

Average density or bulk density $\left(\mathrm{g} / \mathrm{cm}^{3}, \mathrm{~kg} / \mathrm{m}^{3}\right)$ of samples was determined by the following formula:

$\rho=m / V,(2)$

where $\mathrm{m}$ is the mass of the sample $(\mathrm{g})$ and $\mathrm{V}$ is the volume of the sample in its natural state $\left(\mathrm{cm}^{3}\right)$.

Open porosity (\%) of the samples was determined from the following expression:

$\mathrm{P}_{0}=\mathrm{W}-\mathrm{\rho},(2.2 .5)$

where $W$ is the water absorption (\%) and $\rho$ is the density of the samples $\left(\mathrm{g} / \mathrm{cm}^{3}\right)$.

For the experiment run, the installation, which is a container with a double bottom wherein the upper one is made of grillage and the lower one is solid, was made. Both bottoms are opened by lowering down. There is a special outlet with a valve between the upper and lower bottom. The electric stirrer with a reciprocating mechanism for lowering the blades into a container, a feeder for aggregate, and a batcher for filling a liquid are adjacent to the container.

Through a feeder, a certain amount of aggregate is delivered into the container; the latter one is filled with liquid (water, solution) at $20^{\circ} \mathrm{C}$ through the batcher, wherein the water-solid ratio of the aggregate corresponds to the optimum one. Later, a switched on vane mixer falls into a container of low speed of rotation. After a while of mixing, the vane mixer starts to lift. The valve for the liquid drainage has been opened. It also provides time to drain the excess fluid. Then, the lower bottom and upper bottom are alternately brought. The aggregate with the extracted substances is poured into the mixer, and then, the Portland is fed there. The resulting mixture is supplied to the molding and further due to the adopted scheme for the production of wood concrete.

\section{Results}

One of the least important technological processes in the production of wood concrete is a process of aggregate treatment, that is, gentrification. There are two ways for aggregate treatment: the first one is a localization of water- 
soluble substances (WSS) in the body of aggregate by various chemical additives and other ways, and the second one is an extraction of the WSS out of the aggregate.

In practice, the commonly used method of aggregate treatment is its treatment in an aqueous medium [7-14]. However, this method does not effectively remove the WSS out of the aggregate.

Therefore, one of the research areas still remains to be the development of the most effective ways to neutralize the harmful substances in the organic aggregate (both in the wood and from the agricultural crops) and to treat it to obtain the desired properties.

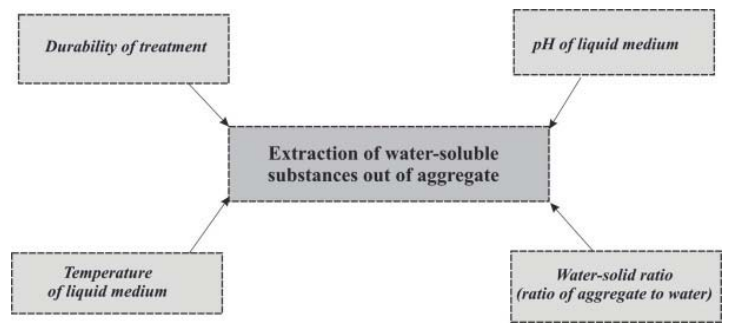

Figure 1 - Factors influencing the process of extracting the water-soluble substances (WSS) of the aggregate

As seen from Figure 1, the strength of multicomponent materials depends on the strength of the links between the structural elements and the strength of the elements. The strength of the constituents (wood and cement) in wood concrete is high-the timber has $15 \mathrm{MPa}$, whereas the cement has $40 \mathrm{MPa}$. At the same time, the strength of the wood is practically not more than 1.5 and $2.2 \mathrm{MPa}$. Consequently, one of the factors that determine the strength of wood concrete is the strength of adhesion of heterogeneous particles. Further study of the adhesion of the contact zone "fly ash-cementorganic aggregate" will identify the factors affecting the mechanical strength characteristics and to establish the most effective methods of organic particle treatment.

Soaking in the water is applied for the treatment of the organic aggregate. In the paper [2,5], the optimal ratio of the aggregate to water is found in the range of $1: 10$ and 1:15, wherein the duration time of 15 min is recommended for soaking.

In Kazakhstan, where there is a lack of forests but there are various agricultural crop wastes that are almost not recycled, using it instead of wood is advisable. The agricultural waste-rice straw and husk reserves are inexhaustible are suitable as the most common raw material for the production of wood concrete for the areas of Southern Kazakhstan, especially in the Kyzylorda region. Moreover, the use of rice husk as the aggregate eliminates the crushing process, as it meets the necessary parameters by granulometric composition.

The following experimental tests have been carried out.

To do this, samples of cubes with an edge of $10 \mathrm{~cm}$ from the wood-concrete mixture of cement were molded: aggregate : water $=1: 0.5: 1.5$. The Portland cement of $38 \mathrm{MPa}$ activity and an aggregate (rice husk, etc.) were used as the binder.

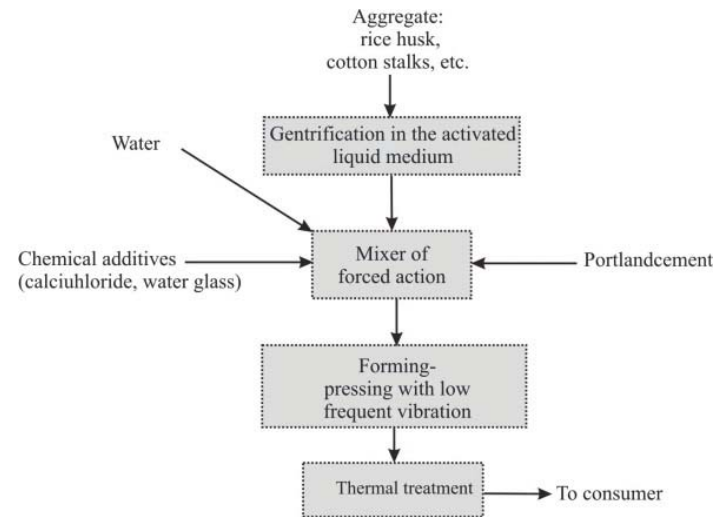

Figure 2 - Flow sheet of wood concrete including a new way of organic aggregate treatment [18] 
The manufacturing technology was carried out according to the diagram shown in Figure 2.

When preparing the samples, the rice husk is soaked in electrochemically activated cathode water by adding it to quicklime in an amount of 1\%-1.5\% by weight of water and adjusting the $\mathrm{pH}$ of the liquid medium to 14-16. To produce the test samples, rice husks are soaked in water at $60^{\circ} \mathrm{C}$ for $10 \mathrm{~min}$. Then, the aggregate is mixed with mineralizer, calcium chloride, administered in an amount of $3 \%$ of the weight of the dry rice husk. After molding by compression, the samples are to be kept for 12 hours. Test results are shown in Table 1.

Table 1 - Impact of the alkalinity medium of the aggregate on the strength of wood concrete

\begin{tabular}{|c|c|c|}
\hline $\mathrm{pH}$ & Soaking time, min & Compression strength characteristics (28 days hardening), MPa \\
\hline 14 & 10 & 2.93 \\
15 & 10 & 3.12 \\
16 & 10 & 3.30 \\
\hline 7 & 10 & 2.2 \\
\hline
\end{tabular}

As seen from the table, the maximum compression strength characteristics of wood concrete (28 days of hardening) in 3.30 MPa are achieved at a liquid medium $\mathrm{pH}$ of 16 .

Volume mass of the produced wood concrete is $600-700 \mathrm{~kg} / \mathrm{m}^{3}$, and the freeze-thaw resistance is $30-35$ cycles. Thereby, in this short time of soaking of the aggregate-rice husk, the lower power compared with the prototype provides a high strength of wood concrete, that is, a qualitative building material. The developed method is recognized as an invention and awarded the patent of the Republic of Kazakhstan [19].

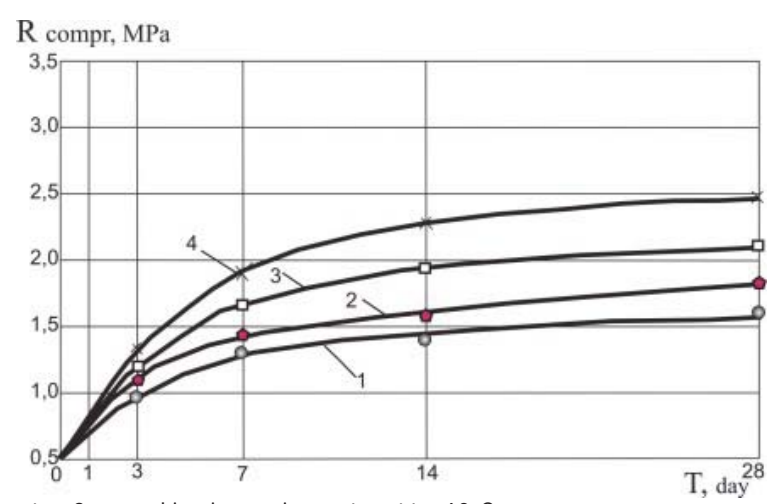

1 - soaking in running water; $2-$ soaking in running water at $\mathrm{t}=60^{\circ} \mathrm{C}$;

3 - treatment in an aqueous solution of $\mathrm{CaCl} 2$ at $\mathrm{t}=60^{\circ} \mathrm{C} ; 4-$ treatment in electrochemically activated water.

Figure 3 - Dependence of wood concrete strength on the ways of processing the organic aggregate-rice husk

To test the effectiveness of the developed method, the experiments for the production of wood-concrete designs on the rice husk treated by different treatment methods were conducted.

As seen in Figure 3, the increased strength of the wood concrete was achieved under gentrification of organic aggregate in the electrochemically activated alkaline water with the addition of $1 \%-1.5 \%$ quicklime.

\section{Discussion}

The developed technological operations improve the physical properties of wood concrete and enhance its strength. In experimental studies, the strength of wood concrete on the rice husk is found to be $2.45 \mathrm{MPa}$. The coefficient of the thermal conductivity of the dry wood concrete is $\sim 0,126 \div 0,147 \mathrm{~W} / \mathrm{m}^{2}$, and that of the wet one is $~ 0,167 \div 0,177 \mathrm{~W} / \mathrm{m}^{2}$.

The new developed method solves the problem of recycling of renewable agricultural waste in the production of effective thermal insulation building materials. Wood concrete made by the proposed method is not inferior to the traditional brick walls, haydite concrete slabs by its thermo-technical characteristics, and its working costs is much lower compared with these materials by its capital cost [20-22]. 


\section{References}

Akchabayev A.A. Improvement of the technological production and development of wood concrete quality. Protection against corrosion and service durability of construction structures and equipment: an analytical review. - M. : 1991. Issue 2. - 32p.

Akchabayev A.A. Fundamentals of advanced technology of pressed wood concrete : diss .... doctor . techn. science. LISI . - St. Petersburg, 1992 . - 297 p.

Bassilkov S.N. Manufacturing technology of environmentally friendly and energy efficient building materials of wood-based raw materials // Building materials, equipment, technologies of the XXI century. №11, 2004. - P. 50-51 .

Shcherbakov A.S. Improving the quality of wood concrete and efficiency of its application. // Development of production and use of efficient designs and products of wood concrete in construction / thes. reports. All-Union Conf. - Moscow: USSR State Committee for Construction, 1981 - 79p.

Nanazashvili I.H. Wood concrete is an efficient building material. - M . 1984 . -122 p .

GOST 19222 - 84. Wood concrete and its products. Technical requirements. - 21p.

Buterin V.M. and others. Recommendations on improving the quality of wood concrete and productivity of enterprises. // Proceedings of the MLTI. Issue. 9, 1976. - P. 178.

Chistyakov A., Suvorova L. Effective products based on rice straw. - Leningrad : Rural constr. -1982 . - № 2 . - P. 15-16.

Recommendation for calculation and manufacturing of products from porous wood concrete. - Moscow: RI of Reinforced Concrete , 1982.

Vikulov V.V. Criterion for assessing the quality of the organic aggregate for wood concrete production. On the cement binder // Proc. Universities. -198 . - № 5. - P.27.

M.G. Rubievskaya. Materials from agricultural wastes // Rural construction . -1984 . - № 9. P - 18.

Akchabayev A.A., Kurmanbekova E.B. Capabilities for technology of gentrification of rice husk aggregate for enhancing strength of wood concrete // Proceedings of the 62nd Scientific and Technical Conference NGASU ( Sibstrin ) - Novosibirsk, 2005.

Usipbekov E.E. Technology of treatment of organic aggregate for cement wood concrete: autoabstr .... candidate . techn. sciences. , Almaty, 1998 .

Akchabayev A.A., Kurmanbekova E.B. Capabilities of the technology upgrading of rice husk filler to increase strength arbolita / / Proceedings of the 62nd Scientific and Technical Conference NGASU ( Sibstrin ) - Novosibirsk , 2005.

Usipbekov EE The technology of preparation of organic filler for cement arbolita : Author. .... Candidate . tehn. Science. , Almaty , 1998.

Evseyev G.A. Investigation of processes of cement hydration in the presence of water-soluble timber extractives (on example of wood concrete production): authoabstr. ... candidate . techn. sciences. -M ., 1971 . -22 p .

Akchabaev A.A., Karlikhanov A.A. Gentrification of wood concrete aggregate // Hydraulic Engineering . -1990 . - № 11. - P. 25-26 .

Uderbayev S.S. Improvement of technology of wood concrete based on vegetable raw materials of the Republic of Kazakhstan / Bulletin of Academy of Sciences of the Republic of Kazakhstan . 2005 . - № 4 . - P.47 -51 .

Prelim. pat. 16644 RK. Method for preparing a wood-concrete mixture / Bissenov K.A., Akchabayev A.A., Uderbayev S.S., Yermakhan B.E., publ . 27.09.2005, Bull . № 10 . - 3p .

Uderbayev S.S. Rice waste - an effective raw material for production of lightweight wood concrete / / Technology of concrete . - M. , 2009 - № 3 - P.24 -25.

Bissenov K.A., Uderbayev S.S. Bases of Asheslags Recycling Wastes in Construction Industry. Proceeding of the International Geotechnical Symposium. Geotechnical engineering for disaster prevention \& reduction, / Edited by Professor Eun Chul Shin (University of Incheon, Korea) \& Professor Askar Zhusupbekov (Eurasian National University, Kazakhstan) 24 -26th of July 2007 . -Yuznhno-Sakhalinsk, - 2007 . - P. 550-553.

Bissenov K.A. , Uderbayev S.S. Optimum principles of the localized structure formation of building materials based on industry wastes. Topical research issues of construction. -Olsztyn, 2006 - - P.459 - 460. 